\title{
The impact of uterine artery embolisation on fibroid volume at 43.6 months in women with symptomatic fibroids at a tertiary-level hospital
}

\author{
R T Mogakane, ${ }^{1}$ MB ChB; Z Abdool, ${ }^{1}$ MMed (O\&G), FCOG (SA); S Ahmad, ${ }^{2}$ FCR (SA); H M Swanepoel, ${ }^{2}$ MB ChB \\ ${ }^{1}$ Department of Obstetrics and Gynaecology, Steve Biko Academic Hospital, Faculty of Health Sciences, University of Pretoria, South Africa \\ ${ }^{2}$ Department of Radiology, Steve Biko Academic Hospital, Faculty of Health Sciences, University of Pretoria, South Africa
}

Corresponding author: Z Abdool (zeelha.abdool@up.ac.za)

\begin{abstract}
Background. Symptomatic uterine fibroids have a significant impact on women's health. Surgical intervention (myomectomy and hysterectomy) has been the mainstay of treatment. Women living with symptomatic uterine fibroids contribute significantly to a growing waiting list for surgery in South African public hospitals. Uterine artery embolisation (UAE) is a newer treatment option and has shown to be a minimally invasive, safe and effective alternative to surgery for such women.

Objective. To evaluate the efficacy of UAE in women with symptomatic fibroid uterus.

Methods. A prospective, observational, single-centre study of 51 women with symptomatic fibroid uterus who underwent UAE at Steve Biko Academic Hospital from February 2007 to November 2012.

Results. A total of 51 women underwent UAE, 3 of whom were lost to follow-up. The remaining 48 women were followed for a mean duration of 43.6 months. There was a statistically significant reduction in the mean uterine and dominant myoma volumes, as well as improvement in the haemoglobin levels $(p=0.001)$. The mean uterine and dominant fibroid volume reductions were $38 \%$ and $58 \%$, respectively. Minor complications were reported in 19\% of the women (fever, post-embolisation syndrome and vaginal fibroid passage were frequently reported complications). Reintervention (hysterectomy and gonadotropin-releasing hormone analogue use) was required in $35 \%$ of women.

Conclusion. UAE has a good clinical effect on fibroid volume reduction. It is a treatment option that can be considered prior to major surgery in a select group of women with symptomatic fibroid uterus.
\end{abstract}

S Afr J Obstet Gynaecol 2017;23(3):97-100. DOI:10.7196/SAJOG.2017.v23i3.1228

Uterine fibroids, also known as leiomyomas, are the most commonly occurring benign tumours of the uterus. ${ }^{[1]}$ Symptomatic fibroid tumours have a major negative impact on the woman's quality of life and reproductive potential. ${ }^{[2]}$ Great health disparities exist worldwide, with African black women experiencing earlier debilitating symptoms and more varied responses to treatment compared with their white counterparts. ${ }^{[3,4]}$

The economic burden of treating symptomatic women is substantial. A recent total cost estimate (direct and indirect) by Soliman et al.$^{[5]}$ in a 2015 systematic review, ranges from USD11 717 - USD25 023 per patient per year after diagnosis or surgery. The true economic impact on South African (SA) public health systems is likely to be higher than the average estimates owing to high disease burden, limited access to treatment, longer waiting times for surgery, low hysterectomy uptake and the presence of severe symptoms among African black women. ${ }^{[4]}$

Surgical management (hysterectomy or myomectomy) has traditionally been the mainstay of treatment (Fig. 1). Recently, umbilical artery embolisation (UAE) and magnetic resonanceguided high-intensity focused ultrasound (MR-g HIFU) has emerged as both an attractive and effective treatment. ${ }^{[6]}$ UAE has proven to be safe and an efficient intervention in women with fibroids who do not desire fertility. A growing body of evidence supports the role of UAE in the treatment of symptomatic fibroids since its introduction by Ravina et al. in $1995 \cdot{ }^{[7-12]}$

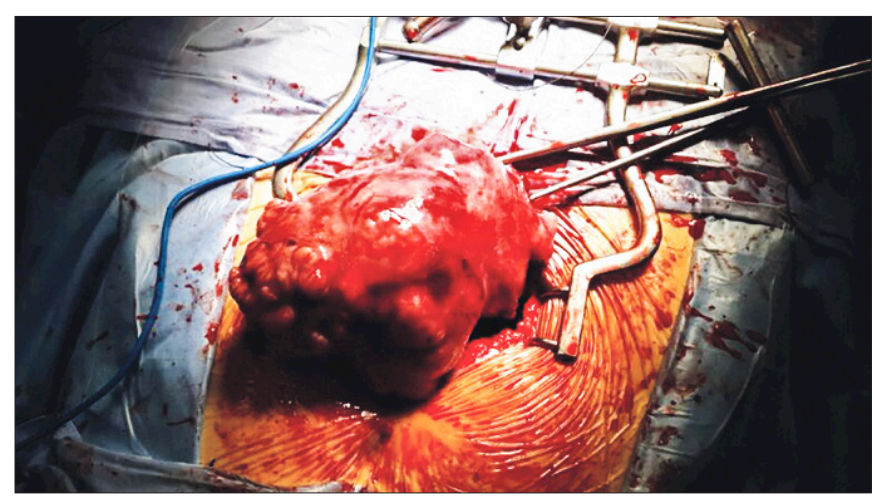

Fig.1. Transabdominal hysterectomy for a large multifibroid uterus.

Since uterine fibroids receive their blood supply via end arteries and do not depend on collateral arteries, occlusion causes ischaemic necrosis and shrinkage (Fig. 2). Incorporation of UAE into routine clinical practice is widely endorsed and its role in heavy menstrual bleeding has been investigated recently. ${ }^{[13]}$ Previously, a local study by Prollius et al. ${ }^{[10]}$ reported a mean reduction in uterine volume of $188 \mathrm{~cm}^{3}$ in 51 women on follow-up at 12 months. There are limited local data on the long-term effect of UAE on symptomatic fibroid volume reduction using follow-up ultrasound imaging. 


\section{Objective}

This study evaluated the impact of UAE on fibroid volume using ultrasound imaging in women with a symptomatic fibroid uterus at 43.6 months.

\section{Methods}

This prospective, observational study was conducted at Steve Biko Academic Hospital, Pretoria, SA. Fifty-one women with symptomatic fibroids were recruited to undergo UAE between February 2007 and November 2012. Patients were invited to participate if they had been diagnosed with symptomatic uterine fibroids (menorrhagia, dysmenorrhoea, pelvic pressure or pain), had a clinical fibroid size of $<20$ weeks, had declined surgical intervention, had no future fertility needs and were able to followup. Women were excluded from the study if they had known allergies to contrast media, previous pelvic radiation/malignancy, renal insufficiency and active pelvic inflammatory disease. All women had a prior examination by a gynaecologist and a consultation with the interventional radiologist. It was decided to include HIV-positive women in the study with CD4 cell counts of $>200$ cells $/ \mu \mathrm{L}$.

The primary outcome of the study assessed the effect of UAE on dominant myoma and total uterine volumes. The secondary outcome measures included adverse events, reintervention rates and follow-up haemoglobin levels.

UAE was performed on all fifty-one women who were recruited from the gynaecology outpatient clinic. Perioperative care was provided by a gynaecologist, anaesthesiologist and intervention radiologist. Preoperative work-up included a full blood count, HIV test, coagulation studies, urea, potassium and creatinine, pap smear and pelvic ultrasound measurement of uterus and dominant fibroid volumes. The volume of the uterus was calculated with the formula for a prolate ellipse $(\mathrm{L} \times \mathrm{W} \times \mathrm{D} \times 0.5233)$ both before and at 3 , 6,12 and 43 months after treatment. Women who were $>40$ years with bleeding symptoms also had an endometrial sample to exclude malignancy. The procedure was performed under spinal or general anaesthesia at the discretion of the anaestheologist. A single dose of prophylactic antibiotic ( $1 \mathrm{~g}$ intravenous cefazolin) was administered before the procedure. The uterine arteries were accessed via a femoral puncture, after which a catheter was inserted. We currently perform trans-radial access instead of femoral puncture. The catheter was initially advanced toward the uterine artery on the contralateral side, followed by the ipsilateral side. An arteriogram was performed to confirm correct placement of the catheters prior to the embolisation. Contour (Boston Scientific, USA) polyvinyl alcohol (PVA) embolisation particles (sizes 150 - 250 and 350 - 500 microns) were inserted to occlude the uterine arteries. At the end of the embolisation, another arteriogram was performed to ensure that the blood supply to the dominant myoma was obstructed (Fig. 3).

Post-procedure analgaesia included paracetamol, tramadol and ibuprofen, alone or in combination. Patients without major complications were discharged 48 hours after the procedure. Haemoglobin, uterus and dominant fibroid volumes were measured at each visit and at 43.6 months after UAE. Data were captured using MS Excel. Statistical analysis was performed using IBM SPSS version 23 (IBM Corp., USA) statistical software. Summary descriptive statistics were used for demographic data and the paired sample

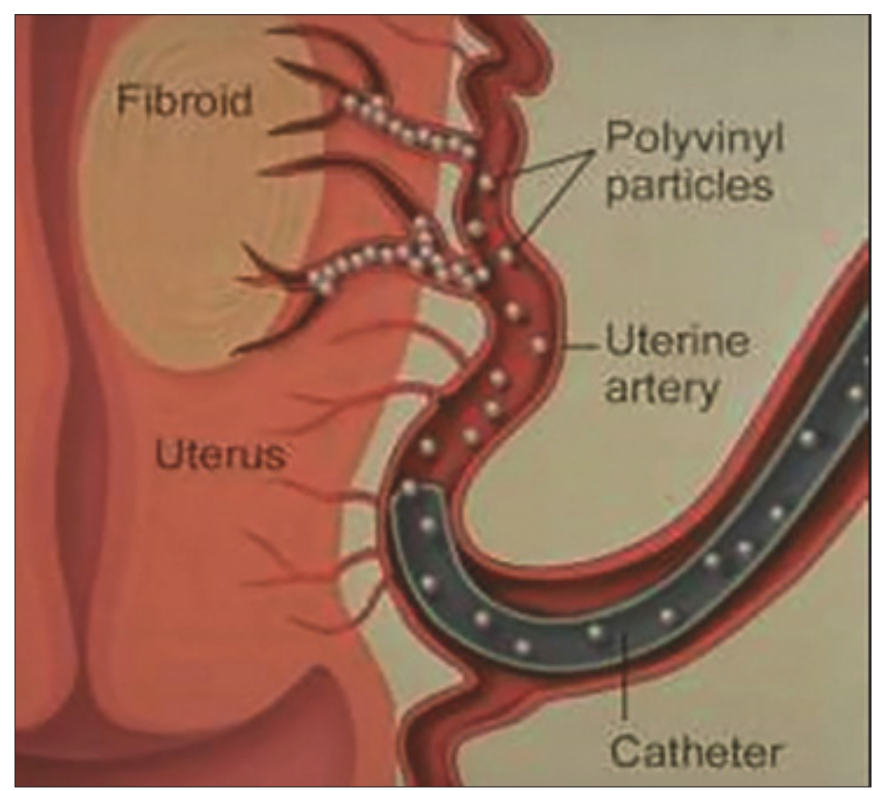

Fig. 2. Injection of PVA particles using a microcatheter during uterine artery embolisation. (Reproduced with permission from Boston Scientific, USA.)

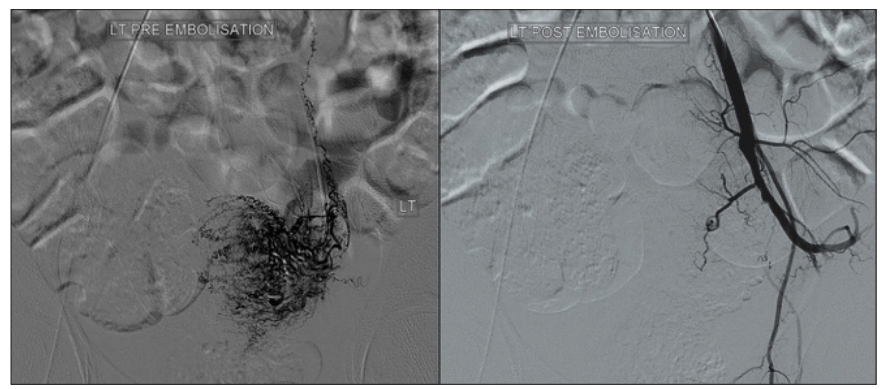

Fig. 3. Fluoroscopic images illustrating visible occlusion of the fibroid blood supply after injection of embolic spheres.

statistics were used to compare the fibroid volumes before and at 43.6 months after UAE. A $p$-value $<0.05$ was considered statistically significant. Ethical approval was granted by the Human Research Ethics Committee of the University of Pretoria (ref. no. 5/2007) and informed consent was obtained from all participants.

\section{Results \\ Demographic characteristics}

A total of 51 women with symptomatic uterine fibroids underwent UAE. Three women were lost to follow-up. Table 1 represents the demographic data of all included women $(n=48)$. The mean age was 45 years (range $34.1-56.2$ ) and the median parity was 2 (range $0-7)$. The majority of the participants were black (89.6\%; $n=43)$. Seven women (14.6\%) were HIV-positive. The mean CD4 cell count was 482.86 cells $/ \mu \mathrm{L}$. Only 2 women were on highly active antiretroviral therapy. The mean (range) uncorrected pre-UAE haemoglobin level was $6.86(6-6.7) \mathrm{g} / \mathrm{dL}$.

The remaining 48 women were followed for a mean duration of up to 43.6 months (range 12 - 69). Bilateral UAE was successful in 47 patients. Unilateral uterine artery spasm was encountered in 1 woman. Bleeding (menorrhagia) and pressure-related symptoms accounted for $72.9 \%$ and $20.8 \%$ of all presenting symptoms, respectively. 
Table 1. Baseline characteristics $(N=48)$

\begin{tabular}{ll}
\hline Characteristic & $\boldsymbol{n}(\%)^{\star}$ \\
\hline Age (years), mean (SD) & $45.34(5.89)$ \\
Parity, mean (SD) & $2.3(1.61)$ \\
Race & \\
$\quad$ Black & $43(89.6)$ \\
$\quad$ White & $2(4.2)$ \\
$\quad$ Other & \\
Uncorrected haemoglobin $(\mathrm{g} / \mathrm{dL})$, mean (SD) & $3(6.2)$ \\
Presenting complaint & $6.86(0.51)$ \\
$\quad$ Bleeding related & \\
$\quad$ Pressure symptoms & $35(72.9)$ \\
HIV-positive & $10(20.8)$ \\
Mean CD4 cell count (cells/ $\mu \mathrm{L})$ & $7(14.6)$ \\
Reintervention & 482.86 \\
Hysterectomy & $17(35.4)$ \\
SD = standard deviation. & $16(33.3)$ \\
${ }^{*}$ Unless otherwise specified. & \\
&
\end{tabular}

Pelage $^{[15]}$ also reported a statistically significant effect on both uterine and dominant fibroid volumes $(p=0.0001)$ in 400 women with symptomatic fibroids on follow-up at 16.7 months. The Royal College of Obstetricians and Gynaecologists reported that at 12 months there is an associated reduction in fibroid volume between $40 \%$ and $70 \%{ }^{[16]}$

In this study, most complications (19\%) were regarded as minor because none required hospitalisation or emergency hysterectomy. There is a lack of data on the safety and efficacy of UAE in symptomatic HIV-positive women. We reported that UAE was not associated with an increase in post-procedure infection and vaginal discharge in HIV-positive women, and all HIV-positive participants had a CD4 count of $\geq 200$ cells $/ \mu \mathrm{L}$. We do, however, acknowledge the small patient number in this study. An earlier study by Prollius et al. ${ }^{[17]}$ did not show overall differences in complication rates between HIV-positive and HIV-negative women. The same study demonstrated an increase in post-procedure complication rates when the CD4 cell count was $<200$ cells/ $\mu \mathrm{L}$. No pregnancies were reported in this study and ovarian function was not assessed.

Table 2. Comparison of mean total uterine and dominant myoma volumes, and mean haemoglobin level before and after UAE at 43.6 months

\begin{tabular}{lll}
\hline Parameter & Pre UAE, mean (SD) & Post UAE, mean (SD) \\
\hline Uterine volume $\left(\mathrm{cm}^{3}\right)$ & $481.22(259.51)$ & $290.05(388.20)$ \\
Dominant myoma $\left(\mathrm{cm}^{3}\right)$ & $79.11(65.98)$ & $33.11(48.82)$ \\
Mean haemoglobin $(\mathrm{g} / \mathrm{dL})^{*}$ & $10.75(2.68)$ & $12.30(2.49)$ \\
*Mean corrected haemoglobin level before UAE procedure. & & 0.001
\end{tabular}

Minor complications were encountered in $19 \%(n=9)$ of women, which included fever, pain, vaginal discharge, fibroid passage and post embolisation syndrome. Treatment included outpatient analgaesics and antibiotics.

At 43.6 months, there was a statistically significant reduction in total uterine (38\%) and dominant fibroid volume (58\%), as well as an improvement in the mean haemoglobin level $(p<0.001)$ (Table 2).

Reintervention in the form of hysterectomy and GnRH analogue administration was required in 17 women $(35.4 \%)$ for persistent symptoms. All women who presented with persistent symptoms declined repeat UAE procedure. Seventy-five percent $(n=12)$ of women had hysterectomies performed within a year of undergoing UAE. The only woman to decline both surgery and repeat UAE opted for a GnRH analogue. She reported complete resolution of symptoms within 8 weeks following a single dose of $3.6 \mathrm{mg}$ subcutaneous zoladex.

\section{Discussion}

This is the first study reporting on the long-term effects of UAE on fibroid volume reduction in patients with symptomatic fibroid uterus using ultrasound imaging. Although MRI is reported to be the superior imaging modality and provides additional clinical information when used in women undergoing UAE, it is expensive and not readily available in all units. ${ }^{[14]}$ Furthermore, a policy of routine MRI use in SA public hospitals prior to UAE is likely to increase costs (directly and indirectly) and waiting times for treatment.

The mean uterine volume was $481.22 \mathrm{~cm}^{3}$ (range 53.66 - 1217 ) prior to the procedure. A mean reduction of $58 \%$ in uterine volume and the lowered need for blood transfusion post UAE is similar to that observed in other studies. Using ultrasound, Walker and
A reintervention rate of $35 \%$ within the study period (43.6 months) is in keeping with other published data. ${ }^{[8]}$ Hysterectomy was performed in the vast majority of women in our study, with only 1 woman opting for medical treatment (3-month course of zoladex). She reported significant improvement in menorrhagia. All women presenting with persistent symptoms post UAE opted against repeat procedure or myomectomy, and were in favour of definitive surgical management. Although reasons for this were not explored, it appears that many women are willing to reconsider personal and cultural beliefs on hysterectomy after failed UAE procedure.

Our article reports outcomes at approximately 3.5 years after UAE. Earlier local publications utilised MRI for the measurement of the uterus and dominant fibroid sizes. ${ }^{[1,12]}$ The use of sonography in our study resulted in similar reintervention rates. The reduction in uterus and fibroid volumes was also comparable. Ultrasound is cost-effective and accessible. Our results indicate that sonography is an invaluable tool in the evaluation and follow-up of women undergoing UAE in resource-poor settings without reducing efficacy and safety.

We acknowledge that validated quality-of-life assessment questionnaires would have improved the quality of data from this study. Furthermore, our study did not compare UAE to other treatment modalities such as hysterectomy and GnRH analogues. Of note is that MR-gHIFU is currently not widely available.

\section{Conclusion}

UAE is an effective alternative to surgery in women with symptomatic fibroid uterus. At 43.6 months there was a statistically significant reduction in the mean uterine and dominant myoma volumes. Approximately one-third of women required 
reintervention. Larger randomised trials are required to evaluate the efficacy of UAE in women with larger uterine volumes and in HIVpositive women.

\section{Acknowledgements. None.}

Author contributions. ZA: conceptualised the study and wrote the initial draft of the manuscript. RTM, SA and HMS: data collection, manuscript editing.

\section{Funding. None.}

\section{Conflicts of interest. None.}

1. Ryan GL, Syrop CH, Van Voorhis BJ. Role, epidemiology, and natural history of benign uterine mass lesions. Clin Obstet Gynecol 2005;48(2):312-324.

2. Brito et al.Uterine leiomyoma: Understanding the impact of symptoms on womens' lives. Reprod Health 2014;11(1):10. https://doi.org/10.1186/1742-4755-11-10

3. Van der Kooij SM, Hehenkamp WJK, Volkers NA, Birnie E, Ankum WM, Reekers JA. Uterine artery embolisation vs hysterectomy in the treatment of symptomatic uterine fibroids: 5 -year outcome from the randomised EMMY trial. Am J Obstet Gynecol 2010; 203(2):105.e1-13. https:/ outcome from the randomised EM.
doi.org/10.1016/j.ajog.2010.01.049

4. Eltouki HM, Modi MN, Weston M, Armstrong AY, Stewart EA. The health disparities of uterine fibroid tumors for African American women: A public health issue. Am J Obstet Gyneco 2014;210(3):194-199. https://doi.org/10.1016/j.ajog.2013.08.008

5. Soliman AM, Yang H, Du EX, Kelkar SS, Winkel C. The direct and indirect costs of uterine fibroid tumors: a systematic review of the literature between 2000 and 2013. Am J Obstet Gynecol 2015;213(2):141-160. https://doi.org/10.1016/j.ajog.2015.03.019

6. Froeling V, Meckelburg K, Scheurig-Muenkler C, et al. Midterm results after uterine artery embolisation versus MR-guided high-intensity focused ultrasound treatment for symptomatic uterine fibroids. Cardiovasc Interven Radiol 2013;36(6):1508-1513. https://doi.org/10.1007/s00270 013-0582-6
7. Ravina JH, Ciraru-Vigneron N, Bouret JM, et al. Arterial embolisation to treat uterine myomata. Lancet 1995;246(8976):671-672.

8. Gupta JK, Sinha A, Lumsden MA, Hickey M. Uterine artery embolisation for symptomatic fibroids. Cochrane Database Syst Rev 2014;12:Cd005073. https://doi.org/10.1002/14651858.CD005073.pub 9. Moss J, Cooper K, Khaund A, et al. Randomised comparison of uterine artery embolisation (UAE)
with surgical treatment in patients with symptomatic fibroids (REST trial): 5-year results. BJOG 2011;118(8):936-944. https://doi.org/10.1111/j.1471-0528.2011.02952.x

10. Prollius A, De Vries C, Loggenberg E, du Plessis A, Nel M, Wessels PH. Uterine artery embolisation for symptomatic fibroids: The effect of the large uterus on outcome. BJOG 2004;111(3):230-242.

11. Lawson A, Cluver C, Olarogun J, et al. Uterine artery embolisation for uterine leiomyomas. S Afr J Obstet Gynaecol 2014;20(1):18-21. https://doi.org/10.7196\%2Fsajog.798

12. Kroncke T, David M. Uterine artery embolisation (UAE) for treatment of myomas. Geburtshilfe und Frauenhielkunde 2014;74(5):433-435. https://doi.org/10.1055/s-0033-1350827

13. Moss J, Christie A. Uterine artery embolisation for heavy menstrual bleeding. Wom Health 2016;12(1):71-77. https://doi.org/10.2217/whe.15.78

14. Spielmann AL, Keogh C, Foster BB, Martin ML, Machan LS. Comparison of MRI and sonography in the preliminary evaluation for fibroid embolisation. Am J Roentgenol 2006;87(6):1499-1504. https:// doi.org/10.2214/AJR.05.1476

15. Walker WJ, Pelage JP. Uterine artery embolisation for symptomatic fibroids; clinical results in 400 women with imaging follow up. BJOG 2002;109(11):1262-1272.

16. The Royal College of Obstetricians and Gynaecologists and The Royal College of Radiologists. Clinical recommendation on the use of uterine artery embolisation (UAE) in the management of fibroids. 3rd edition. London: RCOG and RCR, 2013. https://www.rcog.org.uk/globalassets/ documents/guidelines/23-12-2013_rcog_rcr_uae.pdf (accessed 12 December 2016).

17. Prollius A, du Plessis A, Nel M. Uterine artery embolisation in HIV positive patients. Brie Communication. Int J Obstet and Gynaecol 2005;88(1):67-68. https://doi.org/10.1016/j. ijgo.2004.08.005

Accepted 5 December 2017. 